\title{
Diablo Homolog, Mitochondrial
}

National Cancer Institute

\section{Source}

National Cancer Institute. Diablo Homolog, Mitochondrial. NCI Thesaurus. Code C105653.

Diablo homolog, mitochondrial (239 aa, $27 \mathrm{kDa}$ ) is encoded by the human DIABLO gene. This protein plays a role in the activation of caspase-dependent apoptosis. 